\title{
Developmental heterochrony and the evolution of autistic perception, cognition and behavior
}

\author{
Bernard Crespi
}

\begin{abstract}
Background: Autism is usually conceptualized as a disorder or disease that involves fundamentally abnormal neurodevelopment. In the present work, the hypothesis that a suite of core autism-related traits may commonly represent simple delays or non-completion of typical childhood developmental trajectories is evaluated.

Discussion: A comprehensive review of the literature indicates that, with regard to the four phenotypes of (1) restricted interests and repetitive behavior, (2) short-range and long-range structural and functional brain connectivity, (3) global and local visual perception and processing, and (4) the presence of absolute pitch, the differences between autistic individuals and typically developing individuals closely parallel the differences between younger and older children.

Summary: The results of this study are concordant with a model of 'developmental heterochrony', and suggest that evolutionary extension of child development along the human lineage has potentiated and structured genetic risk for autism and the expression of autistic perception, cognition and behavior.
\end{abstract}

Keywords: Autism, Development, Evolution, Heterochrony

\section{Background}

The autism spectrum is a set of neurodevelopmental conditions characterized and defined by deficits in language and social communication, combined with high expression of restricted interests and repetitive behavior $[1,2]$. Autism is highly heritable [3], and etiologically heterogeneous, such that a broad range of single-gene, genomic, polygenic and environmental variation has been shown to contribute to the development of a similar, convergent suite of overlapping phenotypes $[2,4]$.

The causes of autism have been studied predominantly using genetic, neurological and psychological conceptualizations and approaches $[1,2,4]$. The former two approaches have focused on proximate, molecular-genetic, neurodevelopmental, and synaptic causes of autism considered in terms of dysfunctionality and deficits. By contrast, the latter approach commonly involves consideration of both proximate causes and theoretical psychological models of autism-related phenotypes, with autism considered in terms of cognitive or perceptual 'styles' or 'types', such as weak central coherence [5], high

Correspondence: crespi@sfu.ca

Department of Biological Sciences, Simon Fraser University, 8888 University Drive, Burnaby, British Columbia, V5A 1S6, Canada systemizing relative to empathizing [6], or enhanced perceptual function $[7,8]$. Such styles are atypical but represent extreme manifestations of normally-distributed variation [9], and comprise both relative deficits (mainly in social cognition) and relative strengths (mainly in non-social perception, cognition and task performance).

Evolutionary approaches to the study of autism have been largely restricted to accounts of how phenotypes subject to central deficits in autism, especially language and joint attention, represent uniquely human-evolved or human-elaborated phenotypes (see for example $[10,11]$ ). As such, recent human evolutionary trajectories of increasingly complex social cognition have amplified the genetic and environmentally-based scope for losses and alterations of function that differentially impact human social phenotypes, and potentiate risk of autism-related deficits and changes in cognitive functions. This conceptualization of autism, in terms of ultimate, evolutionary causes, has been useful in motivating studies that compare human evolutionary molecular-genetic and phenotypic changes with alterations that typify neurodevelopmental psychiatric conditions, and in comparing autism with other neurodevelopmental conditions such as schizophrenia $[11,12]$. However, thus far it has provided limited 
direct utility in proximately-based autism research and development of therapies.

Recent human evolution has involved not just the evolution of enhanced general and social cognition, but also large-scale changes to life history, prominently expressed in extension of childhood, defined as the period from birth to sexual maturity and completion of physical growth [13]. Evolutionary expansion of the human childhood stage, and human adult phenotypes at the endpoint of childhood, have usually been described in terms of neoteny: the retention of juvenile characteristics in adults due to evolutionary changes in rates and timing of development $[14,15]$. In particular, human physical, neurological and psychological development processes, and their molecular developmental underpinnings, have evolved to take a considerably longer time, presumably through an extended series of genetically-based, heterochronic changes along the human lineage.

As for social cognition considered as a set of adult phenotypes, evolutionary changes generate scope for genetic, epigenetic and environmental alterations in the timing and rates of cognitive development that manifest as neurodevelopmentally-based psychiatric conditions [15,16]. In particular, under this evolutionary-developmental rubric, autism may commonly involve developmental heterochronic shifts in the timing and rates of neurological and psychological development. As such, the suite of phenotypic alterations that characterize autism spectrum conditions would be expected to involve, in part, simple retention of relatively juvenile traits, as extremes of typical temporal sequences of development. The idea of autism as involving reduced developmental rates has been considered previously in general diagnostic terms, but it has yet to be comprehensively evaluated using data from a suite of autism-related phenotypes, to compare 'autistic' traits with those of typical child development in an explicitly temporal framework. Moreover, such developmental views as do exist center on deficits and dysfunction, rather than on cognitive differences between younger and older individuals that may be more or less conditionally adaptive as opposed to involving constrained sequences from simpler to more complex [17].

In this article, I evaluate the hypothesis that autismrelated traits represent not simply expressions of qualitatively-atypical or 'pathological' development, but instead, relatively juvenile phenotypes that have been retained and expressed for longer than is usual in children undergoing typical development. In this context, rather than concentrate on characteristics of autism that represent deficits or absences, I focus on qualitative differences and similarities between autistic individuals and neurotypical individuals of different ages in perception, cognition and behavior. The primary goal of this article is thus to determine the extent to which autism spectrum phenotypes can be regarded as relatively straightforward consequences of shifts in the timing and rates of neurological and psychological development. To the degree that such developmental heterochrony indeed characterizes the autism spectrum, research into causes and therapies for autism might usefully focus more closely on how genetic and environmental variation mediate the rates and timing of child developmental trajectories and milestones, and causes of variability among children in developmentally-structured cognitive styles. A developmental heterochronic structure to autism also implicates recent evolutionary changes along the human lineage in the potentiation and genetic structuring of autistic perception, cognition, and behavior, and risk for autism spectrum conditions.

\section{Discussion}

\section{Autism and age-related childhood phenotypes}

A set of autistic and autism-related phenotypes, derived from models and reviews of the major features, causes, and correlates of autism, was ascertained based on the availability of (1) reasonably well replicated data showing differences between individuals with autism spectrum phenotypes and typically developing individuals, and (2) data that substantiates differences in these same phenotypes between relatively young, and relatively old, typically developing individuals, usually children. The Web of Science and PubMed databases were systematically searched for articles that met these criteria, using a range of related search terms and cited papers within salient articles. Recent review papers were used for especially well-studied or well-documented topics. For topics where directly comparable data were available, patterns observed for autism spectrum conditions were contrasted with those found in the other most thoroughly studied neurodevelopmental condition, schizophrenia, to evaluate patterns of similarity and differences. This article is thus not a systematic review per se, but takes a comprehensive approach to surveying the literature with regard to conducting robust tests of the hypothesis proposed.

Four sets of phenotypes were chosen for detailed consideration based on the criteria described above: (1) restricted interests and repetitive behavior, (2) short-range and long-range structural and functional brain connectivity, (3) global and local visual perception and information processing, and (4) the presence of absolute pitch in auditory perception and processing.

\section{Restricted interests and repetitive behavior}

Restricted interests and repetitive behavior represent one of the core diagnostic sets of features for the autism spectrum. This set of behaviors, which follows directly 
from Kanner's [18] original descriptions, is defined in The Diagnostic and Statistical Manual of Mental Disorders, fifth edition (DSM-5) as involving some combination of stereotyped or repetitive speech or movement, excessive following of routines and resistance to change, highly intense and focused interests, especially high or low sensory reactivity, and fine motor deficits.

This set of behaviors is also characteristic of typical early child development, and is considered to exhibit important stage-specific adaptive functions [19-22]. Thus, Evans et al. [19], drawing on the foundational work of Gesell et al. [23], described how typically developing 2.5 to 3-year-old children exhibit 'strong preference for sameness in the environment, repetitive ritualized behavior, rigid likes and dislikes, and sometimes acute sensory perceptual awareness of minute details or imperfections in toys or clothes', as well as 'just right' behavior that includes 'attention to detail', 'heightened awareness of how certain clothes feel', and 'ordering of objects in symmetrical patterns', all of which are notably prevalent among children diagnosed with autism. Such behaviors were reported as highest at ages 2 to 4, with declines thereafter. Glenn et al. [21] studied 'routinized and compulsive-like' behaviors, also in typically developing children, and found a significant and linear decline between ages 2 and 11 .

In the developmental psychology literature addressing autism spectrum conditions, restrictive interests and repetitive behavior, especially motor stereotypies, have traditionally been considered as 'immature' behaviors that are normal components of early development but in the autism spectrum have been maintained for longer than normal [22]. Moreover, in children diagnosed with autism spectrum disorder, little atypicality is observed in restrictive interests and repetitive behavior prior to ages 2 or 3 [22].

These findings are in clear agreement with a developmental heterochronic model for autism with regard to restricted interests and repetitive behavior. The causes of the delays per se in developmental attenuation of such behaviors have yet to be investigated; restricted interests and repetitive behavior are found most prominently in autistic individuals with relatively low intellectual and language capacity (although restricted interests are also common among autistic individuals with higher intellectual capacity) [22], and higher levels of their expression are correlated with better performance on the embedded figures test, a relative visuospatial strength found in autism $[24,25]$. However, the strength of the relationship of restricted interests and repetitive behavior with social and language deficits, the other main diagnostic set of features for autism, is moderate to low [26]. To the extent that restricted interests and repetitive behavior exhibit normative adaptive behavioral functions, such as reducing anxiety, decreasing arousal, simplifying complex situations, and fostering a sense of control [20,21], extension of their age-dependent expression may reflect extension of the conditions favoring such behavior. In this context, higher levels of restricted interests and repetitive behavior in autism may be conceptualized in terms of prolonged expression of adaptive, cognitivebehavioral defensive or compensatory functions [27], rather than pathology.

\section{Short-range and long-range structural and functional brain connectivity}

Relatively high levels of short-range functional and structural brain connectivity, concomitant with low levels of long-range connectivity, represent one of the bestreplicated and best-supported findings in the study of autism, being reported for a wide range of data sources (magnetic resonance imaging (MRI), diffusion tensor imaging, and electroencephalography (EEG)), analytic methods, and independent sample populations (see for example [28-35]). The causes of relatively reduced longrange connectivity in autism (Figure 1) remain the subject of intense study, but appear to include, among other causes, larger overall brain size, especially in early childhood [28,36], alterations to cortical minicolumns [37], increased dendritic spine density [38], and genetically-based reductions in development of long-range connections [39]. By contrast, increased relative long-range functional connectivity, due to excessive pruning of short-range connections, has been described in schizophrenia [40-43] and auditory verbal hallucinations [44] (Figure 1).

Typical development from infancy to early adulthood involves a robustly characterized shift from relatively short-range to long-range connectivity, in association with early overproduction of neurons and synapses, differential pruning of relatively short-range connections, and increasing myelinization [45-48] (Figure 1). The rates and timing of cortical growth and pruning have been associated with intellectual capacity [49], but connectivity patterns have yet to be systematically evaluated with regard to variation among typically developing individuals in social and language development, or other relatively specific autism-related phenotypes. In the context of evolved risk for autism and its association with larger brain size, it is useful to note that larger brains exhibit relatively low levels of long-range, compared to short-range, connectivity [50,51]. As such, the recent tripling of human brain size has presumably involved selection for developmental-genetic changes that promote increases in relative long-range connectivity [52], which would increase the genetically and epigenetically-based scope for autism spectrum phenotypes, especially in sets of individuals with larger brains, such as males. 


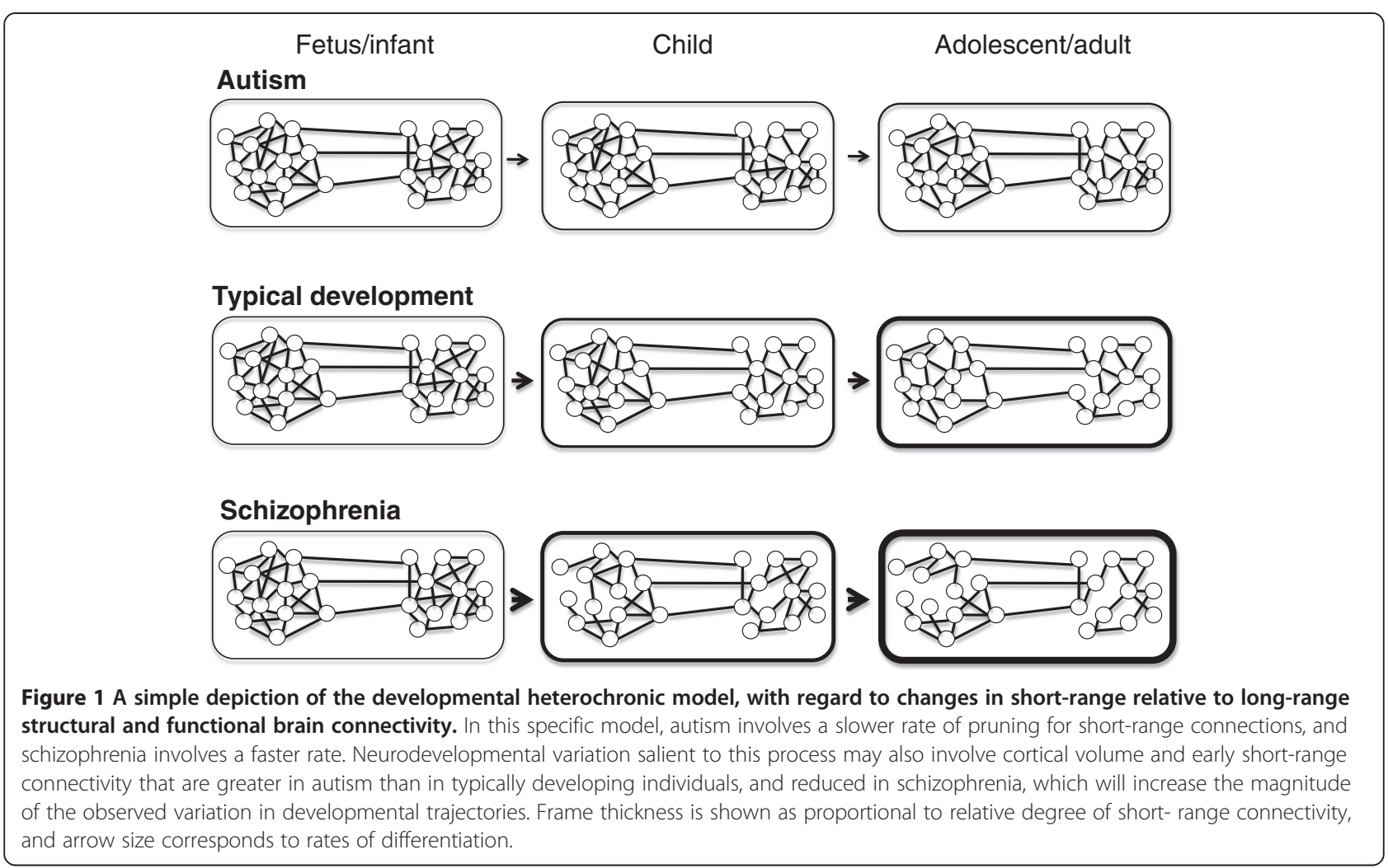

Findings on connectivity in autism, and in typical development, concord with a model of heterochronic alterations, with biases towards shorter-range connectivity in autism representing, at least in part, the result of slower or incomplete connectivity-pattern maturation [30]. In principle, behavioral, cognitive and pharmacological therapies that specifically promote the development of relatively longerrange structural and functional cortical connectivity, especially involving default mode and other 'social brain' regions, represent productive avenues for future research.

\section{Local and global perception and processing}

The 'weak central coherence' theory developed by Francesca Happé posits that autism represents a cognitive 'style' characterized by relatively underdeveloped topdown, context-dependent, gestalt, integrated big-picture perception and cognition, and overdevelopment of detail-focused, context-independent, locally-oriented, partscentered processes $[5,53,54]$. A central prediction of this theory is a bias in the autism spectrum towards perception and processing of local, relative to global, features of environmental stimuli, as epitomized, for example, by higher performance of autistic individuals, or typically developing individuals with more autism-related psychological traits, on the embedded figures test [55-58].

Overwhelming evidence supports the existence in autism spectrum individuals of biases towards local, compared to global, perception and processing of visual information (reviewed in [59]). However, the degree to which such biases are caused by weaker central coherence, compared to more locally-oriented cognition (with typical central coherence), less interference of global structure with local processing, or enhanced locally-oriented perceptual functions, remains to be established [60-64]. In schizophrenia, relative advantages in global compared to local visual processing have been reported by some studies (see for example $[65,66]$ ), but not others (see for example $[67,68]$ ), and the specific tasks deployed usually differ from those used in studies of autism. However, performance on the embedded figures test, or comparable figure-ground tests, is reduced in individuals with schizophrenia compared to controls [69-71], and worse performance on this test has also been associated with higher levels of positive schizotypal traits [58] and severity of disorganized and negative schizophrenia symptoms [71,72] (see also [73]).

In typical development, a large suite of recent studies has demonstrated that younger individuals exhibit a local bias in the perception and processing of visual information, which gradually changes to a global bias from about age 4 to adolescence [74-81]. This developmental shift from local to global bias has, moreover, been linked, among typically developing 6-year-olds, with grey matter reductions in right occipital and parietal visuospatial brain regions, such that anatomical maturation through differentially-local pruning appears to 'fine tune' the visual cortex for processing global visual information as development proceeds [78]. These 
findings provide evidence for links of local and global visual processing with short-range and long-range brain connectivity, indicating that such sets of phenotypes subject to developmental heterochronic effects may be causally connected or otherwise interact.

An especially informative specific example of localglobal visual processing effects in autistic individuals and typically developing children of different ages comes from studies of visual illusions. A suite of reports has provided evidence that autistic individuals are less susceptible than typically developing individuals to visual illusions [5,82-88], which is consistent with enhanced local and context-independent processing in autism $[5,82]$. Moreover, decreased susceptibility to visual illusions has been associated with better performance on the embedded figures test $[83,89,90]$ and block design $[83,84]$, as well as a more systemizing cognitive style [91], which indicates that these different measures of autistic perception and cognition reflect overlap and convergence in their neural underpinnings.

Several studies show evidence for increases with age, across childhood, in visual illusion susceptibility [92-94], although some other reports demonstrate an opposite pattern [95]. Such variation, and variation in results among studies of illusions in autism, may be due in part to differences in the specific tests employed, gender-related variation in illusion susceptibility (with males less susceptible; $[84,90,96])$, and differences in how participants were questioned, regarding whether lines or figures 'looked' different, or 'were' different [85]. Finally, in contrast to autism, schizophrenia involves overall increases in susceptibility to visual illusions, across multiple studies [97-100], which have been interpreted to indicate 'excessive spatial contextual effects of the frame' [100].

These findings generally accord with the developmental heterochronic model, with regard to local and global visual processing. However, more robust tests of the extent to which the local-global processing differences between autistic and typically developing individuals parallel the differences between young and older typically developing children require that the same visual-processing tests be deployed across both groups, and that similar neurophysiological and psychological processes (involving weaker central coherence, stronger local bias, enhanced perceptual function, increased systemizing, or some combination) underlie both the autism-neurotypical and agerelated differences. Indeed, partitioning of perceptual-level effects per se from effects of enhanced visuospatial processing is required for interpretation specifically in terms of local and global effects. Such studies may usefully proceed by testing for local-global visual processing differences and generally enhanced visuospatial skills between typically developing children who vary in their scores on independent metrics of autistic cognition and behavior.

\section{Pitch perception}

Perception of auditory pitch information may involve absolute pitch (specific pitches) or relative pitch (involving intervals between pairs of consecutive tones). Absolute pitch ability refers to the spontaneous identification of a particular pitch label (for example, middle ' $C$ ') when exposed to a musical tone, a skill that requires notably increased auditory-perceptual and discrimination skill [101].

The prevalence of absolute pitch ability has been estimated as about $0.01 \%$ in typical populations, but between $5 \%$ and $11 \%$ in autism, and autism involves notably enhanced abilities in pitch discrimination and memory ([102,103]; review in [8]). A higher level of autism-related traits has also been reported in nonclinical individuals with absolute pitch [104,105], and autism spectrum scores have demonstrated significant positive correlation with abilities to correctly identify absolute pitch [105]. In schizophrenia and schizotypy, pitch discrimination and memory abilities are, by comparison, strongly reduced compared to control individuals [106-109], in association with deficits in basic processing of non-auditory as well as auditory sensory stimuli $[110,111]$.

In typically developing individuals, infants perceive absolute pitch more than relative pitch, and show the ability to track 'extremely fine-grained information' regarding absolute pitch [112]; by contrast, adults depend primarily on relative pitch [112,113]. In their study Stalinski and Stellenberg $[101,114]$ show that this transition involves a monotonic increase in use of relative pitch information, and a decrease in use of absolute pitch information, during development from ages 5 to 12 . The achievement of absolute pitch in typically developing individuals normally requires some level of musical training, which is especially effective at younger ages $[115,116]$. By contrast, in autistic individuals absolute pitch usually develops before any training in musical skills [8].

Absolute pitch perception shows clear evidence of developmental heterochrony across typically developing and autistic individuals, although it is important to note that pitch discrimination abilities cannot necessarily be equated with use of absolute compared to relative pitch information. Moreover, the degree to which absolute pitch perception in autistic individuals recruits the same brain regions as in typical individuals remains to be established. Of particular interest with regard to developmental transitions in pitch perception is conceptualization of the shift as involving the 'unlearning' of absolute pitch perception, because it leads to the generation of overly specific categories of sounds that inhibit learning of higher-level patterns [112,117]. In this general regard, absolute pitch perception in autism may be considered as a specific 
manifestation of enhanced local, detail-oriented perceptual function [8], which does not complete a typical developmental trajectory.

Autism has also been reported to involve enhancements in other modalities of perception, including, for example, vision [118] and tactile sensitivity [119] (reviews in $[7,8])$, but these topics have been subject to less extensive investigation.

\section{Developmental heterochrony, human evolution, and the autism spectrum}

Neurodevelopmental conditions such as autism are usually conceptualized in terms of deficits, disorders, disease, genetic abnormalities, and 'pathological' expression of maladaptive neurological and behavioral phenotypes. These frameworks for understanding and analyzing autism spectrum conditions can be useful for elucidating proximate mechanisms that underlie the causes of autism, but they tend to implicitly assume that neural and psychological development in autism is fundamentally atypical, due to deviation from normative trajectories that starts in the early stages of brain growth and differentiation.

In this article, I have evaluated an alternative, though not necessarily exclusive, model for the etiology of autism, which is based simply on shifts in the timing and rates of infant and child development. This heterochronic developmental model shows clear concordance with well-replicated patterns in the literature on autism and child development in that across the four domains of (1) restricted interests and repetitive behavior, (2) short-range and long-range functional and structural connectivity, (3) local and global visual perception and processing, and (4) auditory pitch perception and processing, the differences between autistic and typically developing individuals mirror the differences between younger and older typically developing individuals. The latter three domains are also expected to be causally associated, in that shorter-range connectivity may subserve more local perception and processing (see for example [63,120]) as well as finer-grained sensory discrimination, although such associations have yet to be studied in a targeted way.

The aspects of autism evaluated here can thus be explained, in part, as involving developmental delays or non-completion that lead to mismatches of chronological age with perceptual, cognitive and behavioral profiles. Other central phenotypes of autism, such as delay and underdevelopment of language, social reciprocity, joint attention, pretend play, imagination, object identification, and other aspects of cognition and social behavior $[1,4,121-123]$, fit naturally into this simple paradigm. This framework may also be useful in understanding some notable behavioral features of autistic syndromes, such as high levels of positive affect in Angelman and Rett syndromes [124,125]. Finally, the developmental heterochronic model may help to explain the strong male bias found in autism, given that typically developing males tend to undergo slower verbal and social development than typically developing females, and thus may be more vulnerable to alterations that notably delay or impede normative development.

The purpose of a developmental heterochronic conceptualization for the autism spectrum is not to equate it with other diagnostic tools or categories, such as developmental delay, but to demonstrate the nature and ultimate, evolutionary causes of the continuity of autism spectrum phenotypes with typical childhood phenotypes, and to help explain the sources of the otherwise inexplicable constellation of morphological, psychological and behavioral traits first described by Kanner and Asperger. Moreover, to the extent that psychological traits of children represent not just immature, underdeveloped phenotypic stages necessary to reach the adaptive mature target stage, but also in many cases ontogenetically-based, stage-specific adaptations that change in qualitative form as development proceeds $[17,126,127]$, retention of relatively 'early-development' traits in autism will necessarily involve some mixture of cognitive enhancements and deficits, as abundantly observed in this literature.

From an evolutionary perspective, genetically-based variation in timing and rates of childhood development is also not unexpected, given that the evolutionary history of human development and life history have followed a similarly structured trajectory of change, towards extension of development in traits ranging from brain gene expression $[128,129]$, to synaptic plasticity [130], synaptic spine development [131] and myelinization [132]. In principle, pathways and sets of genes that underlie growth, neurodevelopment, and synaptic function should thus be expected to overlap between human evolutionary changes (and evolutionary changes earlier in primate and mammalian development) and alterations, as well as segregating variation, that distinguish the autism spectrum from typical development. Such overlaps are reflected in evidence for Darwinian positive selection, and recent human-specific changes in otherwise conserved amino acid positions, in genes such as AHI1, CNTNAP2 and FOXP2 that have been associated with risk of autism [133-139]. A primary use of evidence from positive selection studies in this regard is that they provide evidence of neurodevelopmental functions for specific haplotypes or amino acid variation, which can direct neurogenetic studies along direct, promising paths. Genes that mediate apparent heterochronic changes and variation have been described from taxa other than humans (see for example [140]), and genetic 
variation has been associated with the timing of language acquisition traits in autism [141], but the genetic basis of human childhood developmental timing for other traits related to psychiatric conditions has yet to be investigated in any detail. Genetic variation in agestructured gene expression patterns may indeed help to explain the high heritability of autism, as age-related expression adds an additional, temporal dimension to genetic effects on phenotypic variation.

Developmental heterochronic shifts may, of course, proceed in either of two temporal directions. As described above, autism appears to involve delays and noncompletion of typical developmental trajectories, which can be considered as extensions of developmental neoteny for some set of neurological systems. By contrast, the evidence described here, as well as previous theoretical considerations of schizophrenia in terms of 'failures of neoteny' $[15,16]$, suggest that schizophrenia exhibits elements of premature and accelerated differentiation, the opposite pattern to that observed for autism. Such heterochronic alterations are reflected, for example, in decreased cortical growth and size [142-144], and excessive and relatively early synaptic pruning, neuronal apoptosis and loss of grey matter $[145,146]$, with apparent consequent relative increases in long-range relative to short-range patterns of connectivity, at least for some systems such as the default network $[147,148]$. As in autism, alterations to childhood and adolescent neurodevelopmental timing and rates are expected to involve decreased performance in some set of psychological traits including language and social cognition, although for fundamentally different reasons $[12,149]$.

Further tests of the developmental heterochronic model, and its contribution to helping explain psychological variation among typically developing individuals as well as in autism, schizophrenia, and related conditions, require integration of information from genetic, developmental, and neurological studies, using analyses that explicitly compare multiple neurodevelopmental conditions in longitudinal frameworks (see for example [146]). The timing of developmental shifts in key neurophysiological systems, such as cortical thickness acceleration and deceleration [49], N-methyl-D-aspartate (NMDA) receptor subunit composition [150,151], maturation of primary sensory versus association cortex [152], ratios of excitatory to inhibitory neurotransmission [153-155] and growth and myelinization of long-range connections $[29,152]$, and their genetic bases in such processes as time-dependent production of microRNAs (see for example [156]) and epigenetic regulation of brain maturation by methyl CpG binding protein 2 (MeCP2) [157], should provide relatively strong links between neurodevelopmental timing, its genomic bases, and cognitive outcomes. Such studies will be especially illuminating when conducted in the overall context of recent evolutionary changes in human brain structure and function [139], which are expected to have structured the mechanisms and trajectories of neurodevelopmental shifts. Perhaps most importantly, to the extent that delay or non-completion of cognitive development, rather than primary, pathological alterations, underpin some subset of autism spectrum conditions, autism may be more amenable to treatment than is otherwise believed [158].

\section{Summary}

This article evaluates the hypothesis that some of the major features of autism represent outcomes of shifts in the rate and timing of childhood development, such that traits typical of relatively young individuals are expressed for longer periods, or typical development is not completed. Comprehensive review of the literature indicates that across the four domains of (1) restricted interests and repetitive behavior, (2) short-range relative to longrange functional and structural connectivity, (3) local and global visual perception and processing, and (4) auditory pitch perception and processing, the differences between autistic and typically developing individuals parallel the differences between younger and older typically developing individuals. In contrast to autism, schizophrenia appears to involve developmental heterochronic shifts in the opposite direction, towards accelerated neurodevelopmental differentiation, as reflected, for example, in excessive synaptic pruning and neuronal apoptosis. Given that the evolution of human life history has prominently involved changes in the duration of childhood, these results lend an evolutionary dimension to the analysis of neurodevelopmental psychiatric conditions, and suggest that neurogenetic studies should focus more directly on the causes of variation in rates and timing of childhood neurodevelopmental processes.

\section{Competing interests}

The author confirms that they have no competing interests.

\section{Acknowledgements}

The author is grateful to NSERC for financial support, to the CARTA Center for motivating this work, to S Alam, M Brüne, F Galis and Ze'ev Hochberg for helpful comments, and to Silven Read for technical assistance.

Received: 8 February 2013 Accepted: 22 April 2013

Published: 2 May 2013

\section{References}

1. Frith U: Autism: Explaining the Enigma. Oxford, UK: Blackwell; 1989. 2. Geschwind DH: Advances in autism. Annu Rev Med 2009, 60:367-380.

3. Ronald A, Hoekstra RA: Autism spectrum disorders and autistic traits: a decade of new twin studies. Am J Med Genet B Neuropsychiatr Genet 2011 156B:255-274.

4. Happé F: Autism: An Introduction to Psychological Theory. London, UK: UCL Press; 1994.

5. Happé F: Autism: cognitive deficit or cognitive style? Trends Cogn Sci 1999, 3:216-222. 
6. Baron-Cohen S, Lombardo MV, Auyeung B, Ashwin E, Chakrabarti B, Knickmeyer R: Why are autism spectrum conditions more prevalent in males? PLOS Biol 2011, 9:e1001081.

7. Mottron L, Dawson M, Soulières I, Hubert B, Burack J: Enhanced perceptual functioning in autism: an update, and eight principles of autistic perception. J Autism Dev Disord 2006, 36:27-43.

8. Mottron L, Bouvet L, Bonnel A, Samson F, Burack JA, Dawson M, Heaton P: Veridical mapping in the development of exceptional autistic abilities. Neurosci Biobehav Rev 2012, 37:209-228.

9. Ronald A, Happé F, Price TS, Baron-Cohen S, Plomin R: Phenotypic and genetic overlap between autistic traits at the extremes of the general population. J Am Acad Child Adolesc Psychiatry 2006, 45:1206-1214.

10. Tomasello M, Carpenter M, Call J, Behne T, Moll H: Understanding and sharing intentions: the origins of cultural cognition. Behav Brain Sci 2005 28:675-691.

11. Crespi B: One hundred years of insanity: genomic, psychological, and evolutionary models of autism in relation to schizophrenia. In Handbook of Schizophrenia Spectrum Disorders, Volume I. Conceptual Issues and Neurobiological Advances. Edited by Ritsner MS. New York, NY: Springer; 2011:163-185

12. Crespi B, Badcock C: Psychosis and autism as diametrical disorders of the social brain. Behav Brain Sci 2008, 31:241-320.

13. Bogin B, Smith BH: Evolution of the human life cycle. Am J Hum Biol 1996, 8:703-716.

14. Godfrey LR, Sutherland MR: Paradox of peramorphic paedomorphosis: heterochrony and human evolution. Am J Phys Anthropol 1996, 99:17-42.

15. Brüne M: Neoteny, psychiatric disorders and the social brain: hypotheses on heterochrony and the modularity of the mind. Anthropol Med 2000, 7:301-318.

16. Burns JK: An evolutionary theory of schizophrenia: cortical connectivity, metarepresentation, and the social brain. Behav Brain Sci 2004, 27:831-885.

17. Bjorklund DF: The role of immaturity in human development. Psychol Bull 1997, 122:153-169.

18. Kanner L: Autistic disturbances of affective contact. Nerv Child 1943 2:217-250.

19. Evans DW, Leckman JF, Carter A, Reznick JS, Henshaw D, King RA, Pauls D: Ritual, habit, and perfectionism: the prevalence and development of compulsive-like behavior in normal young children. Child Dev 1997, 68:58-68.

20. Glenn S, Cunningham C: Typical or pathological? Routinized and compulsive-like behaviors in children and young people with Down syndrome. Intellect Dev Disabil 2007, 45:246-256.

21. Glenn S, Cunningham C, Nananidou A: A cross-sectional comparison of routinized and compulsive-like behaviours in typical children aged from 2 to 11 years. Eur J Dev Psychol 2012, 9:614-630

22. Leekam SR, Prior MR, Uljarevic M: Restricted and repetitive behaviors in autism spectrum disorders: a review of research in the last decade. Psychol Bull 2011, 137:562-593.

23. Gesell A, Ames LB, Ilg FL: Infant and the Child in the Culture Today. New York, NY: Harper \& Row; 1974

24. Evans DW, Elliott JM, Packard MG: Visual organization and perceptual closure are related to compulsive-like behavior in typically developing children. Merrill Palmer Q 2001, 47:323-335.

25. Chen YH, Rodgers J, McConachie H: Restricted and repetitive behaviours, sensory processing and cognitive style in children with autism spectrum disorders. J Autism Dev Disord 2009, 39:635-642.

26. Happé $F$, Ronald A, Plomin R: Time to give up on a single explanation for autism. Nat Neurosci 2006, 9:1218-1220.

27. Nesse RM: Maladaptation and natural selection. Q Rev Biol 2005, 80:62-70.

28. Courchesne $\mathrm{E}$, Pierce $\mathrm{K}$ : Why the frontal cortex in autism might be talking only to itself: local over-connectivity but long-distance disconnection. Curr Opin Neurobiol 2005, 15:225-230

29. Geschwind DH, Levitt P: Autism spectrum disorders: developmental disconnection syndromes. Curr Opin Neurobiol 2007, 17:103-111.

30. Neul JL: Unfolding neurodevelopmental disorders: the mystery of developing connections. Nat Med 2011, 17:1353-1355.

31. Testa-Silva G, Loebel A, Giugliano M, de Kock CP, Mansvelder HD, Meredith RM: Hyperconnectivity and slow synapses during early development of medial prefrontal cortex in a mouse model for mental retardation and autism. Cereb Cortex 2012, 22:1333-1342.
32. Barttfeld P, Wicker B, Cukier S, Navarta S, Lew S, Sigman M: A big-world network in ASD: dynamical connectivity analysis reflects a deficit in long-range connections and an excess of short-range connections. Neuropsychologia 2011, 49:254-263.

33. McGrath J, Johnson K, Ecker C, O'Hanlon E, Gill M, Gallagher L, Garavan H: Atypical visuospatial processing in autism: insights from functional connectivity analysis. Autism Res 2012, 5:314-330.

34. von Dem Hagen EA, Stoyanova RS, Baron-Cohen S, Calder AJ: Reduced functional connectivity within and between 'social' resting state networks in autism spectrum conditions. Soc Cogn Affect Neurosci. In press.

35. Washington SD, Gordon EM, Brar J, Warburton S, Sawyer AT, Wolfe A, Mease-Ference ER, Girton L, Hailu A, Mbwana J, Gaillard WD, Kalbfleisch ML, Vanmeter JW: Dysmaturation of the default mode network in autism. Hum Brain Mapp. In press.

36. Froehlich W, Cleveland S, Torres A, Phillips J, Cohen B, Torigoe T, Miller J, Fedele A, Collins J, Smith K, Lotspeich L, Croen LA, Ozonoff S, Lajonchere C, Grether JK, Hallmayer J: Head circumferences in twins with and without autism spectrum disorders. J Autism Dev Disord. In press.

37. Casanova M, Trippe J: Radial cytoarchitecture and patterns of cortical connectivity in autism. Philos Trans R Soc Lond B Biol Sci 2009, 364:1433-1436.

38. Wass S: Distortions and disconnections: disrupted brain connectivity in autism. Brain Cogn 2011, 75:18-28.

39. Rudie JD, Hernandez LM, Brown JA, Beck-Pancer D, Colich NL, Gorrindo P, Thompson PM, Geschwind DH, Bookheimer SY, Levitt P, Dapretto M: Autism-associated promoter variant in MET impacts functional and structural brain networks. Neuron 2012, 75:904-915.

40. Alexander-Bloch AF, Vértes PE, Stidd R, Lalonde F, Clasen L, Rapoport J, Giedd J, Bullmore ET, Gogtay N: The anatomical distance of functional connections predicts brain network topology in health and schizophrenia. Cereb Cortex 2013, 23:127-138.

41. McGlashan TH, Hoffman RE: Schizophrenia as a disorder of developmentally reduced synaptic connectivity. Arch Gen Psychiatry 2000, 57:637-648.

42. Hoffman RE, McGlashan TH: Neural network models of schizophrenia. Neuroscientist 2001, 7:441-454.

43. Siekmeier PJ, Hoffman RE: Enhanced semantic priming in schizophrenia: a computer model based on excessive pruning of local connections in association cortex. Br J Psychiatry 2002, 180:345-350.

44. Hoffman RE, Hampson M: Functional connectivity studies of patients with auditory verbal hallucinations. Front Hum Neurosci 2011, 6:6.

45. Fair DA, Cohen AL, Power JD, Dosenbach NU, Church JA, Miezin FM, Schlaggar BL, Petersen SE: Functional brain networks develop from a "local to distributed" organization. PLoS Comput Biol 2009, 5:e1000381.

46. Supekar K, Musen M, Menon V: Development of large-scale functional brain networks in children. PLOS Biol 2009, 7:e1000157.

47. Dosenbach NU, Nardos B, Cohen AL, Fair DA, Power JD, Church JA, Nelson SM, Wig GS, Vogel AC, Lessov-Schlaggar CN, Barnes KA, Dubis JW, Feczko E, Coalson RS, Pruett JR Jr, Barch DM, Petersen SE, Schlaggar BL: Prediction of individual brain maturity using fMRI. Science 2010, 329:1358-1361.

48. Power JD, Fair DA, Schlaggar BL, Petersen SE: The development of human functional brain networks. Neuron 2010, 67:735-748.

49. Shaw P, Greenstein D, Lerch J, Clasen L, Lenroot R, Gogtay N, Evans A Rapoport J, Giedd J: Intellectual ability and cortical development in children and adolescents. Nature 2006, 440:676-679.

50. Bullmore E, Sporns O: The economy of brain network organization. Nat Rev Neurosci 2012, 13:336-349.

51. Herculano-Houzel S: The remarkable, yet not extraordinary, human brain as a scaled-up primate brain and its associated cost. Proc Natl Acad SCi USA 2012, 109:10661-10668.

52. Preuss TM: The human brain: rewired and running hot. Ann N Y Acad SCi 2011, 1225:E182-E191.

53. Happé F, Frith U: The neuropsychology of autism. Brain 1996 119:1377-1400

54. Happé F, Frith U: The weak coherence account: detail-focused cognitive style in autism spectrum disorders. J Autism Dev Disord 2006, 36:5-25.

55. Shah A, Frith U: An islet of ability in autistic children: a research note. J Child Psychol Psychiatry 1983, 24:613-620.

56. Jolliffe T, Baron-Cohen S: Are people with autism and Asperger syndrome faster than normal on the Embedded Figures Test? J Child Psychol Psychiatry 1997, 38:527-534. 
57. Russell-Smith SN, Maybery MT, Bayliss DM, Sng AA: Support for a link between the local processing bias and social deficits in autism: an investigation of embedded figures test performance in non-clinical individuals. J Autism Dev Disord 2012, 42:2420-2430.

58. Russell-Smith SN, Maybery MT, Bayliss DM: Are the autism and positive schizotypy spectra diametrically opposed in local versus global processing? J Autism Dev Disord 2010, 40:968-977.

59. Brown SM, Bebko JM: Generalization, overselectivity, and discrimination in the autism phenotype: a review. Res Autism Spectr Disord 2012, 6:733-740.

60. Mottron L, Burack JA, larocci G, Belleville S, Enns JT: Locally oriented perception with intact global processing among adolescents with high-functioning autism: evidence from multiple paradigms. J Child Psychol Psychiatry 2003, 44:904-913.

61. Manjaly ZM, Bruning N, Neufang S, Stephan KE, Brieber S, Marshall JC, Kamp-Becker I, Remschmidt H, Herpertz-Dahlmann B, Konrad K, Fink GR: Neurophysiological correlates of relatively enhanced local visual search in autistic adolescents. Neuroimage 2007, 35:283-291.

62. Wang L, Mottron L, Peng D, Berthiaume C, Dawson M: Local bias and local-to-global interference without global deficit: a robust finding in autism under various conditions of attention, exposure time, and visual angle. Cogn Neuropsychol 2007, 24:550-574.

63. Liu Y, Cherkassky VL, Minshew NJ, Just MA: Autonomy of lower-level perception from global processing in autism: evidence from brain activation and functional connectivity. Neuropsychologia 2011, 49:2105-2111.

64. Chamberlain R, McManus IC, Riley H, Rankin Q, Brunswick N: Vocal processing enhancements associated with superior observational drawing are due to enhanced perceptual functioning, not weak central coherence. Q J Exp Psychol (Hove). In press.

65. Granholm E, Perry W, Filoteo JV, Braff D: Hemispheric and attentional contributions to perceptual organization deficits on the global-local task in schizophrenia. Neuropsychology 1999, 13:271-281.

66. Bellgrove MA, Vance A, Bradshaw JL: Local-global processing in early-onset schizophrenia: evidence for an impairment in shifting the spatial scale of attention. Brain Cogn 2003, 51:48-65.

67. Johnson SC, Lowery N, Kohler C, Turetsky BI: Global-local visual processing in schizophrenia: evidence for an early visual processing deficit. Biol Psychiatry 2005, 58:937-946.

68. Landgraf S, Amado I, Purkhart R, Ries J, Olié JP, van der Meer E: Visuo-spatial cognition in schizophrenia: confirmation of a preference for local information processing. Schizophr Res 2011, 127:163-170.

69. Eimon MC, Eimon PL, Cermak SA: Performance of schizophrenic patients on a motor-free visual perception test. Am J Occup Ther 1983, 37:327-332.

70. Pickup GJ, Frith C: Embedded figures and theory of mind in schizophrenia [abstract]. Schizophr Res 1999, 36:148.

71. Longevialle-Hénin R, Bourdel MC, Willard D, Lôo H, Olié JP, Poirier MF, Krebs $\mathrm{MO}$, Amado I: Visuospatial context processing in untreated schizophrenic patients and relation to disorganization syndrome. Encéphale 2005, 31:323-329.

72. Loas G: Visual-spatial processing and dimensions of schizophrenia: a preliminary study on 62 schizophrenic subjects. Eur Psychiatry 2004 9:370-373.

73. Tsakanikos E, Reed P: Visuo-spatial processing and dimensions of schizotypy: figure-ground segregation as a function of psychotic-like features. Pers Individ Dif 2003, 35:703-712.

74. Kovács I, Kozma P, Fehér A, Benedek G: Late maturation of visual spatial integration in humans. Proc Natl Acad Sci USA 1999, 96:12204-12209.

75. Dukette D, Stiles J: The effects of stimulus density on children's analysis of hierarchical patterns. Dev Sci 2001, 4:233-251.

76. Neiworth JJ, Gleichman AJ, Olinick AS, Lamp KE: Global and local processing in adult humans (Homo sapiens), 5-year-old children (Homo sapiens), and adult cotton-top tamarins (Saguinus oedipus). J Comp Psychol 2006, 120:323-330.

77. Poirel N, Mellet E, Houdé O, Pineau A: First came the trees, then the forest: developmental changes during childhood in the processing of visual local-global patterns according to the meaningfulness of the stimuli. Dev Psychol 2008, 44:245-253.

78. Poirel N, Simon G, Cassotti M, Leroux G, Perchey G, Lanoë C, Lubin A, Turbelin MR, Rossi S, Pineau A, Houdé O: The shift from local to global visual processing in 6-year-old children is associated with grey matter loss. PLoS One 2011, 6:e20879.
79. Harrison TB, Stiles J: Hierarchical forms processing in adults and children. J Exp Child Psychol 2009, 103:222-240.

80. Scherf KS, Behrmann M, Kimchi R, Luna B: Emergence of global shape processing continues through adolescence. Child Dev 2009, 80:162-177.

81. Vinter A, Puspitawati I, Witt A: Children's spatial analysis of hierarchical patterns: construction and perception. Dev Psychol 2010, 46:1621-1631.

82. Happé FG: Studying weak central coherence at low levels: children with autism do not succumb to visual illusions. A research note. J Child Psychol Psychiatry 1996, 37:873-877.

83. Bölte S, Holtmann M, Poustka F, Scheurich A, Schmidt L: Gestalt perception and local-global processing in high-functioning autism. J Autism Dev Disord 2007, 37:1493-1504.

84. Ishida R, Kamio Y, Nakamizo S: Perceptual distortions of visual illusions in children with high-functioning autism spectrum disorder. Psychologia 2009, 52:175-187.

85. Mitchell P, Mottron L, Soulières I, Ropar D: Susceptibility to the Shepard illusion in participants with autism: reduced top-down influences within perception? Autism Res 2010, 3:113-119.

86. Ropar D, Mitchell P: Susceptibility to illusions and performance on visuospatial tasks in individuals with autism. J Child Psychol Psychiatry 2001, 42:539-549.

87. Ropar D, Mitchell P: Are individuals with autism and Asperger's syndrome susceptible to visual illusions? J Child Psychol Psychiatry 1999, 40:1283-1293.

88. Hoy JA, Hatton C, Hare D: Weak central coherence: a cross-domain phenomenon specific to autism? Autism 2004, 8:267-281.

89. Witkin HA, Goodenough DR: Cognitive Styles: Essence and Origin. New York, NY: Wiley; 1981

90. Miller RJ: Gender differences in illusion response: the influence of spatial strategy and sex ratio. Sex Roles 2001, 44:209-225.

91. Walter E, Dassonville P, Bochsler TM: A specific autistic trait that modulates visuospatial illusion susceptibility. J Autism Dev Disord 2009 39:339-349.

92. Weintraub DJ: Ebbinghaus illusion - context, contour, and age influence the judged size of a circle amidst circles. J Exp Psychol Hum Percept Perform 1979, 5:353-364.

93. Kaldy Z, Kovacs I: Visual context integration is not fully developed in 4-year-old children. Perception 2003, 32:657-666.

94. Doherty MJ, Campbell NM, Tsuji H, Phillips WA: The Ebbinghaus illusion deceives adults but not young children. Dev Sci 2010, 13:714-721.

95. Brosvic GM, Dihoff RE, Fama J: Age-related susceptibility to the Muller-Lyer and the horizontal-vertical illusions. Percept Mot Skills 2002, 94:229-234

96. Phillips WA, Chapman KL, Berry PD: Size perception is less context-sensitive in males. Perception 2004, 33:79-86.

97. Parnas J, Vianin P, Saebye D, Jansson L, Volmer-Larsen A, Bovet P: Visual binding abilities in the initial and advanced stages of schizophrenia. Acta Psychiatr Scand 2001, 103:171-180.

98. Pessoa VF, Monge-Fuentes V, Simon CY, Suganuma E, Tavares MC: The Müller-Lyer illusion as a tool for schizophrenia screening. Rev Neurosci 2008, 19:91-100.

99. Kantrowitz JT, Butler PD, Schecter I, Silipo G, Javitt DC: Seeing the world dimly: the impact of early visual deficits on visual experience in schizophrenia. Schizophr Bull 2009, 35:1085-1094.

100. Chen Y, McBain R, Norton D, Ongur D: Schizophrenia patients show augmented spatial frame illusion for visual and visuomotor tasks. Neuroscience 2011, 172:419-426.

101. Stalinski SM, Schellenberg EG: Music cognition: a developmental perspective. Top Cogn Sci 2012, 4:485-497.

102. Heaton P, Hudry K, Ludlow A, Hill E: Superior discrimination of speech pitch and its relationship to verbal ability in autism spectrum disorders. Cogn Neuropsychol 2008, 25:771-782.

103. Heaton P, Williams K, Cummins O, Happé F: Autism and pitch processing splinter skills: a group and subgroup analysis. Autism 2008, 12:203-219.

104. Brown WA, Cammuso K, Sachs H, Winklosky B, Mullane J, Bernier R, Svenson S, Arin D, Rosen-Sheidley B, Folstein SE: Autism-related language, personality, and cognition in people with absolute pitch: results of a preliminary study. J Autism Dev Disord 2003, 33:163-167.

105. Dohn A, Garza-Villarreal EA, Heaton P, Vuust P: Do musicians with perfect pitch have more autism traits than musicians without perfect pitch? An empirical study. PLoS One 2012, 7:e37961 
106. Bates TC: The panmodal sensory imprecision hypothesis of schizophrenia: reduced auditory precision in schizotypy. Pers Individ Dif 2005, 38:437-449.

107. Leitman DI, Foxe JJ, Butler PD, Saperstein A, Revheim N, Javitt DC: Sensory contributions to impaired prosodic processing in schizophrenia. Biol Psychiatry 2005, 58:56-61

108. Force RB, Venables NC, Sponheim SR: An auditory processing abnormality specific to liability for schizophrenia. Schizophr Res 2008, 103:298-310.

109. Leitman DI, Sehatpour P, Higgins BA, Foxe JJ, Silipo G, Javitt DC: Sensory deficits and distributed hierarchical dysfunction in schizophrenia. Am J Psychiatry 2010, 167:818-827.

110. Javitt DC: Sensory processing in schizophrenia: neither simple nor intact. Schizophr Bull 2009, 35:1059-1064.

111. Javitt DC: When doors of perception close: bottom-up models of disrupted cognition in schizophrenia. Annu Rev Clin Psychol 2009, 5:249-275.

112. Saffran JR, Griepentrog GJ: Absolute pitch in infant auditory learning: evidence for developmental reorganization. Dev Psychol 2001, 37:74-85.

113. Saffran JR: Musical learning and language development. Ann N Y Acad Sci 2003, 999:397-401

114. Stalinski SM, Schellenberg EG: Shifting perceptions: developmental changes in judgments of melodic similarity. Dev Psychol 2010, 46:1799-1803.

115. Crozier JB, Robinson EA, Ewing V: Etiology of absolute judgments of pitch. Bulletin de Psychologie 1977, 30:792-803.

116. Sakakibara A: Why are people able to acquire absolute pitch only during early childhood? Training age and acquisition of absolute pitch. Japanese J Educ Psychol 2004, 52:485-496.

117. Bossomaier T, Snyder A: Absolute pitch accessible to everyone by turning off part of the brain? Organised Sound 2004, 9:181-189.

118. Samson F, Mottron L, Soulières I, Zeffiro TA: Enhanced visual functioning in autism: an ALE meta-analysis. Hum Brain Mapp 2012, 33:1553-1581.

119. Cascio C, McGlone F, Folger S, Tannan V, Baranek G, Pelphrey KA, Essick G: Tactile perception in adults with autism: a multidimensional psychophysical study. J Autism Dev Disord 2008, 38:127-137.

120. Damarla SR, Keller TA, Kana RK, Cherkassky VL, Williams DL, Minshew NJ, Just MA: Cortical underconnectivity coupled with preserved visuospatial cognition in autism: evidence from an fMRI study of an embedded figures task. Autism Res 2010, 3:273-279.

121. Riviere A: Language and theory of mind: vygotsky, skinner and beyond In Behaviour Analysis in Theory and Practice: Contributions \& Controversies. Edited by Blackman DE, Lejeune H. Hove, UK: Lawrence Erlbaum Associates; 1990:199-213.

122. Fernyhough C: The dialogic mind: a dialogic approach to the higher mental functions. New Ideas Psychol 1996, 14:47-62

123. Woodard CR, Van Reet J: Object identification and imagination: an alternative to the meta-representational explanation of autism. J Autism Dev Disord 2011, 41:213-226.

124. Watson P, Black G, Ramsden S, Barrow M, Super M, Kerr B, Clayton-Smith J: Angelman syndrome phenotype associated with mutations in MECP2: a gene encoding a methyl CpG binding protein. J Med Genet 2001, 38:224-228.

125. Oliver C, Horsler K, Berg K, Bellamy G, Dick K, Griffiths E: Genomic imprinting and the expression of affect in Angelman syndrome: what's in the smile? J Child Psychol Psychiatry 2007, 48:571-579.

126. Bjorklund DF, Periss V, Causey K: The benefits of youth. Eur J Dev Psychol 2009, 6:120-137.

127. Thompson-Schill SL, Ramscar M, Chrysikou EG: Cognition without control: when a little frontal lobe goes a long way. Curr Dir Psychol Sci 2009, 18:259-263

128. Somel M, Franz H, Yan Z, Lorenc A, Guo S, Giger T, Kelso J, Nickel B, Dannemann M, Bahn S, Webster MJ, Weickert CS, Lachmann M, Pääbo S, Khaitovich P: Transcriptional neoteny in the human brain. Proc Natl Acad Sci USA 2009, 106:5743-5748

129. Liu X, Somel M, Tang L, Yan Z, Jiang X, Guo S, Yuan Y, He L, Oleksiak A, Zhang Y, Li N, Hu Y, Chen W, Qiu Z, Pääbo S, Khaitovich P: Extension of cortical synaptic development distinguishes humans from chimpanzees and macaques. Genome Res 2012, 22:611-622.

130. Bufill E, Agustí J, Blesa R: Human neoteny revisited: the case of synaptic plasticity. Am J Hum Biol 2011, 23:729-739.

131. Petanjek Z, Judaš M, Šimic G, Rasin MR, Uylings HB, Rakic $P$, Kostovic I: Extraordinary neoteny of synaptic spines in the human prefrontal cortex. Proc Natl Acad Sci USA 2011, 108:13281-13286.
132. Miller DJ, Duka T, Stimpson CD, Schapiro SJ, Baze WB, McArthur MJ, Fobbs AJ, Sousa AM, Sestan N, Wildman DE, Lipovich L, Kuzawa CW, Hof PR, Sherwood CC: Prolonged myelination in human neocortical evolution. Proc Natl Acad Sci USA 2012, 109:16480-16485.

133. Gong X, Jia M, Ruan Y, Shuang M, Liu J, Wu S, Guo Y, Yang J, Ling Y, Yang $X$, Zhang D: Association between the FOXP2 gene and autistic disorder in Chinese population. Am J Med Genet B Neuropsychiatr Genet 2004, 127B:113-116.

134. Amann-Zalcenstein D, Avidan N, Kanyas K, Ebstein RP, Kohn Y, Hamdan A, Ben-Asher E, Karni O, Mujaheed M, Segman RH, Maier W, Macciardi F, Beckmann JS, Lancet D, Lerer B: AHI1, a pivotal neurodevelopmental gene, and C6orf217 are associated with susceptibility to schizophrenia. Eur J Hum Genet 2006, 14:1111-11119.

135. Spiteri E, Konopka G, Coppola G, Bomar J, Oldham M, Ou J, Vernes SC, Fisher SE, Ren B, Geschwind DH: Identification of the transcriptional targets of FOXP2: a gene linked to speech and language, in developing human brain. Am J Hum Genet 2007, 81:1144-1157.

136. Alvarez Retuerto Al, Cantor RM, Gleeson JG, Ustaszewska A, Schackwitz WS Pennacchio LA, Geschwind DH: Association of common variants in the Joubert syndrome gene (AHI1) with autism. Hum Mol Genet 2008, 17:3887-3896

137. Torri F, Akelai A, Lupoli S, Sironi M, Amann-Zalcenstein D, Fumagalli M, Dal Fiume C, Ben-Asher E, Kanyas K, Cagliani R, Cozzi P, Trombetti G, Strik Lievers L, Salvi E, Orro A, Beckmann JS, Lancet D, Kohn Y, Milanesi L, Ebstein RB, Lerer B, Macciardi F: Fine mapping of AHI1 as a schizophrenia susceptibility gene: from association to evolutionary evidence. FASEB $J$ 2010, 24:3066-3082.

138. Mukamel Z, Konopka G, Wexler E, Osborn GE, Dong H, Bergman MY, Levitt P, Geschwind DH: Regulation of MET by FOXP2: genes implicated in higher cognitive dysfunction and autism risk. J Neurosci 2011 31:11437-11442

139. Somel M, Liu X, Khaitovich P: Human brain evolution: transcripts, metabolites and their regulators. Nat Rev Neurosci 2013, 14:112-127.

140. Dollé $P$, Dierich $A$, LeMeur $M$, Schimmang $T$, Schuhbaur B, Chambon $P$, Duboule D: Disruption of the Hoxd-13 gene induces localized heterochrony leading to mice with neotenic limbs. Cell 1993, 75:431-441

141. Alarcón M, Cantor RM, Liu J, Gilliam TC, Geschwind DH, Autism Genetic Research Exchange Consortium: Evidence for a language quantitative trait locus on chromosome $7 q$ in multiplex autism families. Am J Hum Genet 2002, 70:60-71.

142. Arango C, Moreno C, Martínez S, Parellada M, Desco M, Moreno D, Fraguas D, Gogtay N, James A, Rapoport J: Longitudinal brain changes in early-onset psychosis. Schizophr Bull 2008, 34:341-353.

143. Levitt JJ, Bobrow L, Lucia D, Srinivasan P: A selective review of volumetric and morphometric imaging in schizophrenia. Curr Top Behav Neurosci 2010, 4:243-281.

144. Knickmeyer RC, Wang J, Zhu H, Geng X, Woolson S, Hamer RM, Konneker T, Lin W, Styner M, Gilmore JH: Common variants in psychiatric risk genes predict brain structure at birth. Cereb Cortex. In press.

145. Rapoport JL, Addington A, Frangou S: The neurodevelopmental model of schizophrenia: what can very early onset cases tell us? Curr Psychiatry Rep 2005, 7:81-82.

146. Shaw P, Gogtay N, Rapoport J: Childhood psychiatric disorders as anomalies in neurodevelopmental trajectories. Hum Brain Mapp 2010, 31:917-925.

147. Karbasforoushan $\mathrm{H}$, Woodward ND: Resting-state networks In schizophrenia. Curr Top Med Chem 2012, 12:2404-2414.

148. Whitfield-Gabrieli S, Ford JM: Default mode network activity and connectivity in psychopathology. Annu Rev Clin Psychol 2012, 8:49-76.

149. Crespi B, Stead P, Elliot M: Comparative genomics of autism and schizophrenia. Proc Natl Acad Sci USA 2010, 107:1736-1741.

150. Matta JA, Ashby MC, Sanz-Clemente A, Roche KW, Isaac JT: mGluR5 and NMDA receptors drive the experience- and activity-dependent NMDA receptor NR2B to NR2A subunit switch. Neuron 2011, 70:339-351.

151. Matosin N, Newell KA: Metabotropic glutamate receptor 5 in the pathology and treatment of schizophrenia. Neurosci Biobehav Rev 2012 37:256-268

152. Rosenzweig I, Vukadinovic Z, Turner AJ, Catani M: Neuroconnectivity and valproic acid: the myelin hypothesis. Neurosci Biobehav Rev 2012 $36: 1848-1856$ 
153. Rolls ET, Deco G: A computational neuroscience approach to schizophrenia and its onset. Neurosci Biobehav Rev 2011, 35:1644-1653.

154. Rubenstein $\mathrm{J}$ : Three hypotheses for developmental defects that may underlie some forms of autism spectrum disorder. Curr Opin Neurol 2010, 23:118-123.

155. Ben-Ari Y, Khalilov I, Kahle KT, Cherubini E: The GABA excitatory/inhibitory shift in brain maturation and neurological disorders. Neuroscientist 2012, 18:467-486.

156. Li Q, Bian S, Hong J, Kawase-Koga Y, Zhu E, Zheng Y, Yang L, Sun T: Timing specific requirement of microRNA function is essential for embryonic and postnatal hippocampal development. PLoS One 2011, 6:e26000.

157. Cohen S, Gabel HW, Hemberg M, Hutchinson AN, Sadacca LA, Ebert DH, Harmin DA, Greenberg RS, Verdine VK, Zhou Z, Wetsel WC, West AE, Greenberg ME: Genome-wide activity-dependent MeCP2 phosphorylation regulates nervous system development and function. Neuron 2011, 72:72-85.

158. Ehninger D, Li W, Fox K, Stryker MP, Silva AJ: Reversing neurodevelopmental disorders in adults. Neuron 2008, 60:950-960.

doi:10.1186/1741-7015-11-119

Cite this article as: Crespi: Developmental heterochrony and the evolution of autistic perception, cognition and behavior. BMC Medicine 2013 11:119.

\section{Submit your next manuscript to BioMed Central and take full advantage of:}

- Convenient online submission

- Thorough peer review

- No space constraints or color figure charges

- Immediate publication on acceptance

- Inclusion in PubMed, CAS, Scopus and Google Scholar

- Research which is freely available for redistribution 